\title{
PENGEMBANGAN WISATA TREKKING DI KAWASAN DANAU BUYAN, DESA PANCASARI, KABUPATEN BULELENG
}

\author{
I Ketut Budayasa \\ E-mail:markbudayasa@yahoo.co.id
}

\begin{abstract}
Buleleng regency in North Bali has many areas that could potentially be developed into tourist destination areas, one of them being Lake Buyan Forest Area which is very potential to be a trekking tour as an alternative form of tourist attraction offering new experiences to tourists. The study was aimed at determining the potential of the forest area as a place for trekking activities, community participation and tourists in the development of the area, and to identify the effective strategies in its development. Data collection techniques used in this study were observation, structured interviews with tourists who were conducting trekking activities and in-depth interview with the related people and the tourists visiting Lake Buyan. The research method used was descriptive-qualitative and SWOT analyses. The study results showed that the physical and non-physical potential owned by forest area of Buyan Lake could be developed into a tourist trekking area, which was also supported by the SWOT analysis. In the process its development, the participation of the related people was an important factor.
\end{abstract}

Keywords: trekking tourism development, participation, sustainable tourism

\section{Pendahuluan}

Pariwisata Bali dikenal karena keunikan budayanya, namun sesungguhnya daerah ini juga memiliki potensi alam yang indah yang telah menjadi daya tarik wisata. Kenyataan di lapangan menunjukkan bahwa pengembangan pariwisata alam telah mendukung pengembangan pariwisata Bali sehingga menambah daya tariknya. Dengan memadukan antara keunikan budaya dan keindahan alam, tercipta kegiatan pengelolaan wisata dengan menekankan pada aktivitas wisata yang tidak merusak lingkungan tetapi menjaga lingkungan agar tetap lestari dan harmonis. Kegiatan masyarakat terkait dengan alam merupakan satu keunikan yang bisa dilihat, dirasakan, dan dihayati, misalnya wisata tirta, memancing, berkemah, lintas alam, penjelajahan, wisata ilmiah, dan wisata trekking. 
Salah satu kabupaten di Bali yang memiliki kekayaan dan keindahan hutan dan dapat dikembangkan sebagai daya tarik wisata adalah Kabupaten Buleleng. Potensi alam yang dimiliki Kabupaten Buleleng sudah dikembangkan namun belum optimal sebagai Daerah Tujuan Wisata (DTW). Kawasan Hutan Taman Wisata Alam (TWA) Danau Buyan di Desa Pancasari memiliki potensi yang dapat dikembangkan menjadi wisata minat khusus yaitu wisata trekking, namun hingga kini pengembangannya masih dalam tahap awal dan terbatas. Letak Danau Buyan berdekatan dengan daya tarik wisata Kebun Raya Eka Karya. Danau Buyan dan Danau Tamblingan keduanya memiliki panorama yang sangat indah dan sering disebut sebagai danau kembar, karena kedua danau tersebut letaknya bersebelahan.

Danau Tamblingan lebih dikenal oleh wisatawan mancanegara dan wisatawan domestik khususnya wisatawan yang gemar olah raga minat khusus trekking. Danau Buyan memiliki potensi untuk dikembangkan dan diberdayakan agar menjadi sebuah DTW yang dapat menyamai Danau Tamblingan. Masyarakat setempat kurang menyadari potensi hutan di Kawasan Hutan TWA Danau Buyan dan lebih memilih bekerja di sektor pertanian dan perkebunan. Hal ini dikarenakan masyarakat tidak menyadari potensi hutan yang dimiliki dan juga penguasaan bahasa asing sebagai bahasa pengantar belum memadai.

Lingkungan serta kondisi hutan di Kawasan Hutan TWA Danau Buyan yang bervariasi dengan kekayaan alam yaitu flora dan fauna serta danau dan lereng perbukitan yang menghijau, sangat potensial untuk dijadikan wisata minat khusus yaitu wisata trekking. Potensi sumber daya alam yang menjadi andalan bagi kawasan TWA Danau Buyan mencakup hayati dan non-hayati, diantaranya potensi flora dan fauna yang berada di kawasan Konservasi Hutan Lindung. Bagi wisatawan yang menjelajahi alam pegunungan TWA Danau Buyan akan dapat menemukan sebuah keunikan serta pemandangan khas hutan yang masih asri serta pemandangan danau yang sangat indah. Potensi ini dapat menjadikan kawasan ini menjadi sebuah DTW yang menarik di masa depan.

Penulisan artikel ini bertujuan untuk mengetahui potensi yang dimiliki oleh Kawasan Hutan TWA Danau Buyan sebagai pendukung kegiatan wisata trekking, menganalisis peranserta masyarakat dan wisatawan dalam pengembangan wisata trekking di Kawasan Hutan TWA Danau Buyan, dan merumuskan strategi yang efektif dalam pengembangan wisata trekking di Kawasan Hutan TWA Danau Buyan.

\section{Teori dan Metode}

Teori yang digunakan dalam artikel ini adalah teori perencanaan. Menurut Anom (2005:32), perencanaan adalah suatu proses mempersiapkan sesuatu secara sistematis kegiatan-kegiatan yang akan dilakukan untuk 
mencapai tujuan. Dengan perencanaan dapat disusun urutan-urutan kegiatan menurut skala prioritas dalam mencapai tujuan. Wearing dan Neil (dalam Hakim, 2004:141) menyatakan bahwa dalam sebuah perencanaan, idealnya harus mencakup tahapan-tahapan yaitu studi kelayakan, penentuan tujuan, analisis dan sintesis, kebijakan dan fomulasi rencana, rekomendasi, implementasi dan monitoring. Sedangkan menurut Watson dan Heywood (dalam Hakim, 2004:144) suatu perencanaan harus mampu menjelaskan keterkaitan yang nyata antara kepentingan ekonomi, ekologi, dan sosial. Dengan mempertimbangkan aspek ekonomi, ekologi, dan sosial, perencanaan dipandang akan mampu memperkuat perencanaan daerah, sekaligus menjamin redistribusi manfaat pengelolaan sumber daya alam secara berkesinambungan antara generasi, dan yang lebih penting adanya keadilan perolehan keuntungan dari penggunaan sumber daya yang ada.

Perencanaan suatu daerah untuktujuan pariwisata harus pulaberdasarkan suatu studi yang khusus dibuat untuk itu, dengan memperhatikan perlindungan terhadap lingkungan alam dan budaya di daerah sekitar perencanaan fisik. Suatu daerah untuk tujuan pariwisata harus didasarkan atas penelitian yang sesuai dengan lingkungan alam sekitar dengan memperhatikan faktor geografis yang lebih luas dan tidak meninjau dari segi administrasi saja. Rencana dan penelitian yang berhubungan dengan pengembangan kepariwisataan pada suatu daerah harus memperhatikan faktor ekologi daerah yang bersangkutan.

Untuk mengkaji permasalahan dalam artikel ini, analisis data didasarkan pada penggunaan teknik analisis deskriptif kualitatif, yaitu teknik analisis data yang lebih banyak memanfaatkan dan mengumpulkan informasi dengan mendalami fenomena yang diteliti. Satu fenomena sampai pada fenomena lain yang mempunyai kaitan dengan variabel yang diteliti (Maleong, 1994). Meskipun demikian, untuk memperoleh gambaran lebih lengkap tentang objek yang diteliti, artikel ini juga ditunjang oleh data atau informasi yang bersifat kuantitatif. Kajian terhadap permasalahan juga dilakukan dengan menggali informasi untuk mengetahui potensi, kekuatan, kelemahan, peluang, dan tantangan serta rencana strategi pengembangan Kawasan Hutan TWA Danau Buyan di Desa Pancasari, Kecamatan Sukasada, Kabupaten Buleleng. Secara keseluruhan artikel ini menggunakan analisis deskriptif kualitatif dan didukung oleh data kuantitatif, baik yang diperoleh melalui sumber data primer maupun sumber data sekunder.

\section{Potensi Wisata Trekking di Kawasan Hutan TWA Danau Buyan}

Potensi yang dimiliki Kawasan Hutan TWA Danau Buyan mencakup potensi fisik dan potensi non fisik. Masing-masing potensi tersebut adalah sebagai berikut. Potensi fisik berupa keadaan alam yang menjadi daya tarik, rute atau jalur trekking dan lokasi-lokasi tertentu yang menjadi daya tarik 


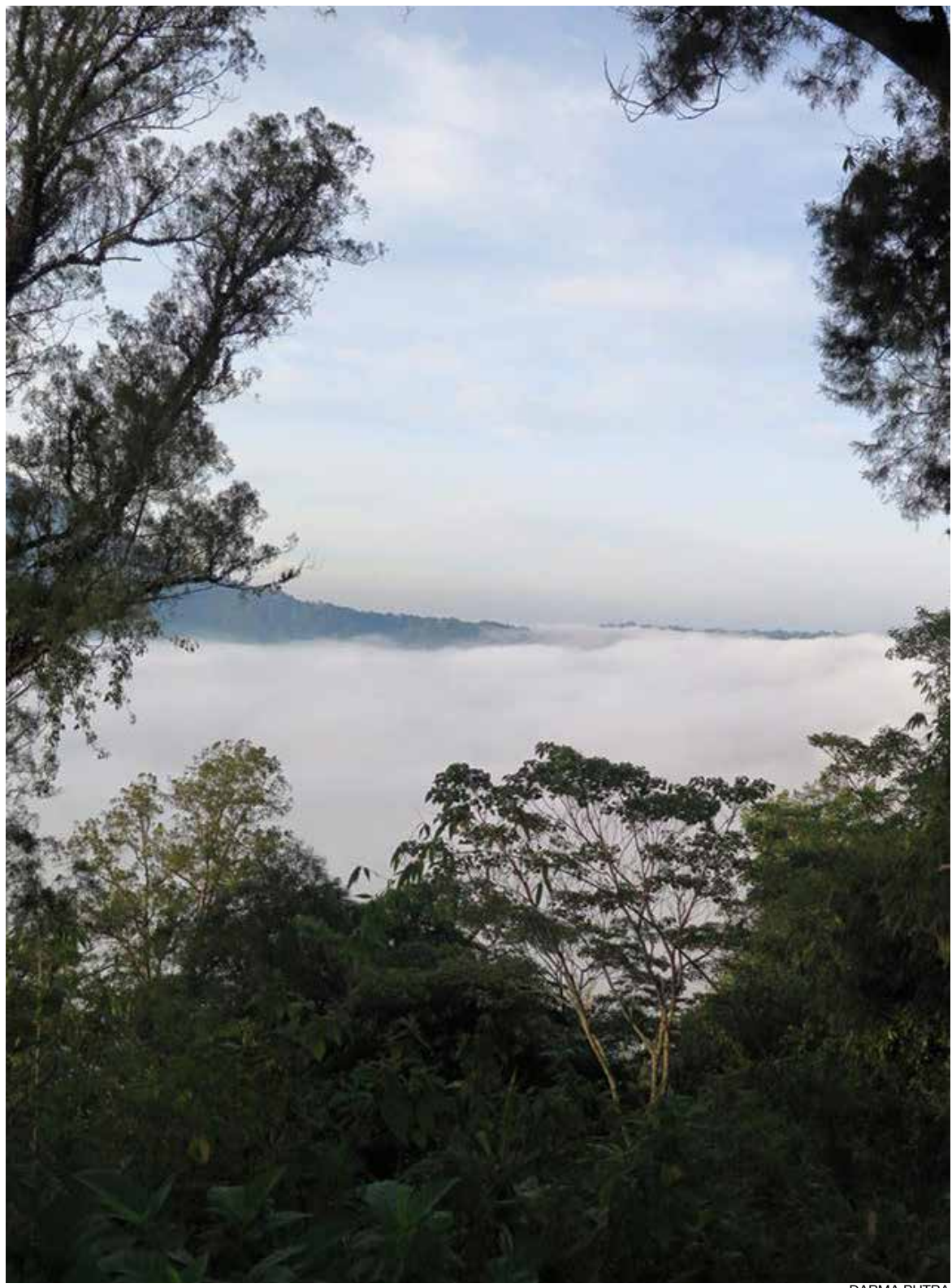

Foto 1. Pemandangan alam yang indah di kawasan hutan antara Danau Tamblingan dan Danau Buyan.

wisata trekking. Sejuknya udara di dalam hutan, keadaan hutan yang masih alami dengan berbagai jenis pohon, keindahan panorama Danau Buyan dan tebing-tebing yang curam sepanjang pesisir danau, menjadikan kawasan ini memiliki daya tarik yang sangat unik (Lihat Foto 1).

Selain itu kondisi perairan danau yang tenang dengan udara yang sejuk, 
berpotensi untuk melaksanakan kegiatan wisata tirta seperti memancing, cannoing, dan berperahu mengelilingi danau. Pada beberapa tempat, wisatawan dapat menikmati pemandangan sambil beristirahat melepaskan lelah, melakukan aktivitas lainnya seperti wisata spiritual. Wisata spiritual berpotensi untuk dilaksanakan karena terdapat beberapa pura seperti Pelinggih Ida Bethara Nyoman dan Pura Guna Anyar.

Potensi non-fisik seperti potensi budaya, tumbuh dan berkembang di masyarakat Desa Pancasari berupa adat istiadat, agama, mata pencaharian, kesenian, kebiasaan serta cara hidup. Potensi non-fisik berupa kesenian di Desa Pancasari untuk mengiringi kegiatan ritual tradisional berupa Tari Sang Hyang Penyalin.

\section{Peran Masyarakat dan Wisatawan dalam Pengembangan Wisata Trekking}

Dalam pengembangan wisata trekking di kawasan Hutan TWA Danau Buyan, peran serta masyarakat dan wisatawan sangat dibutuhkan guna mewujudkan kawasan Hutan TWA Danau Buyan sebagai sebuah daerah tujuan wisata yang dikenal oleh wisatawan domestik maupun wisatawan mancanegara.

Peran serta masyarakat mengandung arti keterlibatan masyarakat dalam pembangunan diri, kehidupan dan partisipasi terhadap segala kegiatan yang ada di sekitar lingkungannya. Peran serta masyarakat yang berada di lingkungan Kawasan Hutan TWA Danau Buyan, perlu mendapat prioritas pada aktivitas yang berhubungan dengan pengembangan daya tarik wisata. Agar terwujud rencana pengembangan wisata trekking dengan baik, harus memperhatikan keadaan alam, karakter daerah, harapan, serta peran serta masyarakat lokal terhadap wisata trekking yang akan dikembangkan.

Masyarakat Pancasari sebanyak 76,5\% menyatakan sangat setuju terhadap dikembangkannya potensi Kawasan Hutan TWA Danau Buyan sebagai wisata trekking. Pada umumnya mereka memiliki harapan agar kegiatan wisata trekking tidak mengganggu kelestarian dan kealamian lingkungan alam dan hutan di Kawasan Hutan TWA Danau Buyan. Perlunya peran serta masyarakat dalam pengembangan wisata trekking tersebut juga diperkuat oleh perwakilan Perbekel Desa Pancasari yaitu Ir. Gusti Ngurah Arjana, MP (Wawancara 11-08-2012) yang mengatakan sebagai berikut.

...pada prinsipnya sangat setuju dengan adanya kegiatan wisata trekking. Kebetulan saat ini sedang dikembangkan wisata trekking yang merupakan salah satu potensi wisata yang telah ada di desa yang berbasis kemasyarakatan, sehingga masyarakat bawah dapat ikut menikmati percikan dari wisata tersebut. Dalam pelaksanaannya tidak lepas dari konsep rambu-rambu atau pelestarian.

Pendapat tersebut mendapat dukungan dari salah satu tokoh masyarakat 
Desa Pancasari yaitu I Putu Setiawan (wawancara 15-08-201), seperti dalam penuturannya berikut ini.

Saya sangat mendukung dengan adanya pengembangan kegiatan wisata trekking karena menurut saya wisata trekking adalah bagian dari pariwisata dengan alasan yaitu melalui wisata trekking kami bisa memperkenalkan kekayaan alam yang ada di Desa Pancasari khususnya di TWA Danau Buyan, dan untuk meningkatkan pariwisata di desa kami.

Hasil penelitian menunjukkan bahwa semua responden bersikap dan menyatakan setuju terhadap pengembangan potensi Kawasan Hutan TWA Danau Buyan. Hal ini sejalan dengan Maheswari (2010) yang menemukan bahwa masyarakat sangat setuju terhadap pengembangan ekowisata di kawasan Danau Buyan, karena wisatawan umumnya menyukai panorama, keindahan alam dan keanekaragaman flora dan fauna Danau Buyan. Adapun sikap masyarakat terhadap pengembangan potensi Kawasan Wisata Danau Buyan seperti Tabel 1.

Tabel 1 Sikap Masyarakat terhadap Pengembangan TWA Danau Buyan

\begin{tabular}{|c|c|c|c|}
\hline \multirow{2}{*}{ No } & \multicolumn{3}{|c|}{ Jumlah Responden } \\
\hline & Kategori Jawaban & Orang & Persentase (\%) \\
\hline 1 & Sangat setuju & 13 & 76,5 \\
\hline 2 & Setuju & 4 & 23,5 \\
\hline 3 & Ragu-ragu & - & - \\
\hline 4 & Tidak setuju & - & - \\
\hline 5 & Sangat tidak setuju & - & - \\
\hline & Jumlah & 17 & 100 \\
\hline
\end{tabular}

Sumber: Data diolah dari penelitian, 2013.

Selain menyebarkan kuesioner kepada masyarakat setempat untuk mengetahui pendapat mereka mengenai pengembangan potensi wisata di kawasan Danau Buyan, kuesioner juga disebarkan kepada wisatawan yang sedang melakukan kegiatan wisata trekking di TWA Danau Buyan. Jumlah wisatawan yang dimintai pendapat dengan kuesioner adalah 40 orang, terdiri dari 20 orang wisatawan asing dan 20 orang wisatawan domestik.

Sebanyak 14 orang (70\%) wisatawan asing mendapatkan informasi mengenai wisata trekking di TWA Danau Buyan dari travel agent, sedangkan untuk wisatawan domestik, 14 orang (70\%) mendapatkan informasi mengenai keberadaan wisata trekking di kawasan TWA Danau Buyan dari teman maupun relasi. Ini berarti wisata trekking di TWA Danau Buyan sudah dikenal di kalangan wisatawan, baik wisatawan asing maupun wisatawan domestik. Adapun sumber informasi tentang wisata trekking di 
TWA Danau Buyan seperti Tabel 2.

Tabel 2 Sumber Informasi Kawasan Hutan TWA Danau Buyan

\begin{tabular}{llcccc}
\hline \multirow{2}{*}{ No Sumber Informasi } & \multicolumn{2}{c}{ W. Asing } & \multicolumn{2}{c}{ W. Domestik } \\
\cline { 2 - 5 } & & Orang & $\%$ & Orang & $\%$ \\
\hline 1 & Teman/Relasi & - & - & 14 & 70 \\
2 & Taravel Agent & 14 & 70 & 4 & 20 \\
3 & Koran/Majalah & 3 & 15 & - & - \\
4 & Brosur & 3 & 15 & - & - \\
5 & Lain-lain & - & - & 2 & 10 \\
\hline & Jumlah & 20 & 100 & 20 & 100 \\
\hline
\end{tabular}

Sumber: Diolah dari Penelitian 2013.

\section{Strategi Pengembangan Wisata Trekking}

Pengembangan wisata trekking, membutuhkan perencanaan pariwisata yang baik agar diperoleh hasil yang optimal sesuai dengan tujuan yang ingin dicapai. Untuk menyusun sebuah strategi, analisis SWOT (strength, weaknesses, opportunity, dan threat) merupakan pendekatan yang dapat digunakan untuk mengkaji kondisi dan keadaan fisik dan serta lingkungan di sekitar Kawasan Hutan TWA Danau Buyan. Strategi tersebut nantinya akan dapat dikembangkan sebagai salah satu masukan dalam kaitan pengembangan wisata trekking.

Analisis SWOT digunakan untuk mengetahui kekuatan (strength), kelemahan (weaknesses), peluang (opportunities) dan ancaman (threats).

Kekuatan adalah segala sesuatu yang dapat dikembangkan sebagai andalan pengembangan wisata trekking di Kawasan Hutan Danau Buyan, berupa potensi fisik dan potensi non-fisik sehingga nantinya dapat bertahan dan bersaing dengan objek wisata lain. Beberapa keunggulan dan kelebihan TWA Buyan sebagai wisata trekking, seperti pada Tabel 3.

Kelemahan suatu daya tarik wisata merupakan kondisi dan keadaan pada objek tersebut yang kurang menguntungkan, sehingga perlu dilakukan langkah-langkah untuk mengatasinya. Beberapa kelemahan yang ada di Kawasan Hutan TWA Danau Buyan, seperti pada Tabel 3.

Peluang merupakan factor-faktor dari luar yang dapat mendorong pengembangan wisata trekking di Kawasan Hutan TWA Danau Buyan. Beberapa peluang yang ada di Kawasan Hutan TWA Danau Buyan, seperti pada Tabel 3 .

Ancaman adalah segala sesuatu yang harus diantisipasi agar tidak menimbulkan kerugian terhadap pengembangan obyek wisata. Beberapa ancaman yang ada di Kawasan Hutan TWA Danau Buyan, seperti Tabel 3. 
Tabel 3 Mastrik SWOT Potensi Kawasan Hutan TWA Danau Buyan

\begin{tabular}{|c|c|c|}
\hline & Kekuatan (S) & Kelemahan (W) \\
\hline $\begin{array}{l}\text { Matr } \\
\text { SW0 }\end{array}$ & $\begin{array}{l}\text { 1. Potensi Hutan Di TWA } \\
\text { Danau Buyan } \\
\text { 2. Panorama danau Buyan } \\
\text { yang indah dan alami } \\
\text { 3. Potensi wisata tirta } \\
\text { 4. Kegiatan ritual Tari Sang- } \\
\text { hyang Penyalin } \\
\text { 5. Masih terpeliharanya } \\
\text { warisan sejarah leluhur } \\
\end{array}$ & $\begin{array}{l}\text { 1. Sumber daya manusia dan } \\
\text { kelembagaan yang belum } \\
\text { siap } \\
\text { 2. Promosi yang belum mak- } \\
\text { simal tentang keberadaan } \\
\text { kawasan TWA Danau } \\
\text { Buyan } \\
\text { 3. Aksesibilitas rute trekking } \\
\text { belum memadai } \\
\end{array}$ \\
\hline Pelu & Strategi S - O & Strategi W - O \\
\hline $\begin{array}{l}\text { 1.Adanya kecendrungan } \\
\text { pariwisata alternatif } \\
\text { 2.Adanya kemajuan teknolo- } \\
\text { gi, baik teknologi informa- } \\
\text { si maupun transportasi }\end{array}$ & \begin{tabular}{|} 
1.Strategi rancangan produk \\
wisata trekking, spiritual, \\
lingkungan dan kerakyatan \\
2. Strategi pengembangan \\
wisata trekking di kawasan \\
TWA Danau Buyan untuk \\
membuka lapangan kerja \\
sampingan
\end{tabular} & $\begin{array}{l}\text { 1.Strategi pengembangan } \\
\text { kelembagaan dan SDM } \\
\text { Pariwisata } \\
\text { 2.Stategi pengembangan sa- } \\
\text { rana dan prasarana pokok } \\
\text { dan penunjang aktivitas } \\
\text { kepariwisataan di kawasan } \\
\text { TWA Danau Buyan } \\
\end{array}$ \\
\hline Anc & Strat & Strat \\
\hline $\begin{array}{l}\text { 1.Ancaman terhadap mutu } \\
\text { kawasan Hutan TWA } \\
\text { Danau Buyan } \\
\text { 2. Ancaman terhadap pence- } \\
\text { maran dan kerusakan } \\
\text { lingkungan hutan }\end{array}$ & $\begin{array}{l}\text { 1. Strategi peningkatan } \\
\text { keamanan kawasan } \\
\text { 2.Pemerhatian lingkungan } \\
\text { dalam pengembangan ka- } \\
\text { wasan wisata yang sesuai } \\
\text { dengan kriteria zona-zona } \\
\text { yang ditetapkan }\end{array}$ & $\begin{array}{l}\text { 1.Strategi penetrasi pas- } \\
\text { ar dan promosi wisata } \\
\text { trekkinh di kawasan TWA } \\
\text { Danau Buyan } \\
\text { 2.Kerjasama dengan Biro } \\
\text { Perjalanan Wisata/Travel } \\
\text { Agent }\end{array}$ \\
\hline
\end{tabular}

Sumber: Hasil Penelitian 2013.

Berdasarkan matrik SWOT pada Tabel 3, strategi yang dapat dirumuskan adalah sebagai berikut.

\section{1) Strategi S-O (strength-opportunities)}

Strategi S-O merupakan strategi yang menggunakan kekuatan untuk memanfaatkan peluang. Adapun implementasinya berikut ini.

(1) Rancangan produk wisata trekking

Strategi ini dapat dilakukan untuk pemetaan potensi wisata trekking secara partisipatif, bekerjasama dengan stakeholders untuk mengetahui kekayaan potensi yang terdapat di Kawasan Hutan TWA Danau Buyan, khususnya yang terkait wisata trekking. Pemetaan metode partisipatif, merupakan proses pemetaan yang dilakukan dengan melibatkan perwakilan masyarakat, Konservasi Sumber Daya Alam (KSDA) dan pemerintah. Hasil dari pemetaan dapat dijadikan dasar untuk pembuatan strategi pengembangan produk wisata trekking. Kegiatan wisata trekking yang dijalankan oleh masyarakat, pihak swasta dan investor harus mendapat dukungan dari instansi terkait, dalam hal ini Dinas Pariwisata dan Kebudayaan Kabupaten 
Buleleng. Sinergi dengan pemerintah dapat mempercepat kemajuan perkembangan pengelolaan wisata trekking di Kawasan Hutan TWA Danau Buyan. Segala kebutuhan masyarakat desa terkait dengan pengembangan pariwisata di Kawasan Hutan TWA Danau Buyan dapat didialogkan dengan stakeholders.

(2) Membuka lapangan kerja

Wisata trekking adalah kegiatan wisatawan menyusuri hutan untuk melihat dan merasakan kesejukan udara di dalam hutan, berjalan di bawah rindangnya berbagai jenis pohon, mendengarkan kicauan berbagai jenis burung yang hidup di Kawasan Hutan TWA Danau Buyan, dan menyusuri pinggiran danau sampai di depan Pura Ulun Danu. Keindahan panorama hutan dan pesisir Danau Buyan dapat dikemas menjadi wisata trekking. Aktivitas wisata trekking diharapkan mampu membuka lapangan pekerjaan baru bagi generasi muda masyarakat Desa Pancasari.

\section{2) Strategi W-O (weaknesses-opportunities)}

Strategi W-O merupakan strategi yang meminimalkan kelemahan untuk memanfaatkan peluang, diimplementasikan berikut ini.

(1) Pengembangan kelembagaan dan SDM Pariwisata

Peningkatan kapasitas masyarakat dilakukan melalui pelatihan. Dalam menjalankan dan melaksanakan program wisata trekking di Kawasan Hutan TWA Danau Buyan, masyarakat di Desa Pancasari diharapkan ikut terlibat didalamnya dan berpartisipasi dalam kemajuan daerahnya. Agar seluruh komponen masyarakat dapat terlibat dengan baik, maka kemampuan (kapasitas) masyarakat harus ditingkatkan melalui pelatihan (training), lokakarya (workshop) maupun upaya-upaya lainnya. Untuk mewujudkan pemberian pelatihan dan peningkatan kualitas masyarakat di desa Pancasari di bidang pariwisata, diperlukan kerjasama dengan lembaga-lembaga pelatihan pariwisata, sehingga masyarakat mendapat pembelajaran dan pelatihan dari instruktur yang ahli di bidang pariwisata, khususnya wisata trekking. Selain itu pembekalan bahasa asing terutama bahasa Inggris kepada masyarakat setempat juga sangat diperlukan, terutama untuk berkomunikasi dengan wisatawan asing.

(2) Membantu dan menyediakan sarana pokok dan sarana penunjang kepariwisataan

Menjaga kealamian hutan dan keindahan Danau Buyan adalah mutlak harus dilakukan baik oleh masyarakat, wisatawan, maupun Konservasi Sumber Daya Alam Buyan (KSDA). Untuk memberikan kepuasan dan kesan yang baik kepada wisatawan pada saat mereka berkunjung ke Kawasan Hutan TWA Danau Buyan, maka pembangunan sarana pokok dan sarana penunjang kepariwisataan perlu dilakukan, seperti 
memperbaiki fasilitas toilet, penambahan tempat pembuangan sampah, menyediakan shelter, tempat peristirahatan, dan menyediakan tempat makan.

\section{3) Strategi S-T (strength- threats)}

Merupakan strategi yang menggunakan kekuatan untuk mengatasi ancaman, diimplementasikan sebagai berikut.

(1) Peningkatan keamanan

Keamanan adalah sesuatu yang sangat penting bagi kenyamanan wisatawan, juga merupakan salah satu faktor penentu keberlanjutan pariwisata di suatu daerah. Keamanan juga sangat diperlukan dalam pengembangan wisata trekking di Kawasan Hutan TWA Danau Buyan. Untuk lebih mengintensifkan keamanan wilayah TWA Danau Buyan, diperlukan koordinasi yang lebih baik untuk memperkuat keamanan wilayah. Pada tingkat mikro, desa Pancasari perlu membangun sistim keamanan secara terpadu dengan model tradisional. Sistem keamanan model tradisional dimotori oleh perangkat keamanan tradisional Bali yaitu pecalang.

(2) Pemerhati terhadap lingkungan dalam pengembangan kawasan wisata yang sesuai dengan kriteria zona-zona peruntukan

Kelemahan yang dimiliki oleh Kawasan Hutan TWA Danau Buyan adalah adanya penebang hutan di areal Kawasan Hutan Danau Buyan. Penebangan hutan untuk kepentingan pribadi dan trekking motor liar. Walaupun sudah ditempatkan Polisi Hutan, tetapi dengan luasnya hutan di Kawasan Hutan TWA Danau Buyan, pengamanan belum sepenuhnya dapat menjangkau seluruh areal kawasan hutan. Untuk itu diperlukan penambahan pegawai di KSDA TWA Danau Buyan agar lebih intensif dalam mengawasi hutan dari aktivitas penebangan hutan liar dan trekking motor liar di Kawasan Hutan ataupun di kawasan zona konservasi dan zona preservasi. Kenyamanan wisatawan perlu dijaga oleh petugas dari KSDA, meskipun mereka sedang melaksanakan tugas pengawasan dan pemantauan hutan.

\section{4) Strategi W-T (weakness- threats)}

Merupakan strategi yang meminimalkan kelemahan dan menghindari ancaman, diimplementasikan sebagai berikut.

(1) Penetrasi pasar dan promosi wisata trekking

Untuk memperkenalkan wisata trekking di Kawasan Hutan TWA Danau Buyan, promosi adalah salah satu hal yang mutlak harus dilakukan. Media cetak ataupun elektronik dapat dipergunakan untuk membantu mempromosikan keberadaan wisata trekking di Kawasan Hutan TWA Danau Buyan.

(2) Menjalin kerjasama dengan jaringan wisata trekking atau travel agent Salah satu upaya terpenting dalam membangun sebuah gerakan 
wisata trekking adalah dengan membangun jaringan kerjasama seluas-luasnya, terutama dengan jaringan wisata trekking yang ada di Bali maupun dengan biro perjalanan wisata.

\section{Penutup}

Hutan di Kawasan Hutan TWA Danau Buyan memiliki potensi berupa berbagai jenis tumbuh-tumbuhan, pohon-pohonan, satwa liar, dan rute/ jalur dari Buper Buyan I menuju Buper Buyan II. Dengan potensi tersebut Kawasan Hutan TWA Danau Buyan sangat cocok dikembangkan menjadi wisata trekking, karena dapat memberikan kesempatan kepada para pecinta alam untuk menikmati indahnya pemandangan alam hutan dengan nuansa spritual yang tinggi.

Partisipasi masyarakat dalam mendukung pengembangan wisata trekking di Kawasan Hutan TWA Danau Buyan antara lain dalam membangun fasilitas penunjang kepariwisataan, seperti membangun gardu pengintaian burung, penambahan shelter di beberapa tempat, mengikuti pendidikan dan pelatihan di bidang kepariwisataan, menyediakan snack bagi tamu yang mengikuti trekking, menyediakan fasilitas toilet umum, dan ikut menjaga keamanan dan kenyamanan lingkungan dengan melibatkan pecalang.

Strategi pengembangan kegiatan wisata trekking adalah sebagai berikut. Strategi S-O (strength-opportunities), yaitu strategi rancangan produk wisata trekking dilakukan dengan pemetaan potensi wisata trekking secara partisipatif bekerjasama dengan stakeholders untuk mengetahui kekayaan potensi yang terdapat di Kawasan Hutan TWA Danau Buyan. Strategi $\mathrm{W}-\mathrm{O}$ (weaknesses- opportunities), yaitu dilakukan dengan pengembangan kelembagaan, SDM, dan pengembangan sarana prasarana penunjang kepariwisataan. Strategi S-T (strength-threat), yaitu melalui peningkatan keamanan sesuai dengan zona-zona yang ditetapkan, penambahan jumlah pegawai KSDA atau Polisi Hutan yang bertugas di Kawasan Hutan TWA Danau Buyan, serta pemerhatian lingkungan yang sesuai dengan kriteria zona-zona yang ditetapkan. Strategi W-T (weakness threat) yaitu dengan penetrasi pasar dan pengembangan kerjasama pengelolaan dengan Biro Perjalanan Wisata.

Disarankan kepada pemerintah daerah agar membantu pengembangan fasilitas penunjang pariwisata seperti pembangunan shelter, gardu pandang, perbaikan toilet, pembangunan lobby, melakukan perbaikan rute trekking khususnya dari Buper I menuju Buyan II, sehingga wisatawan merasa nyaman dan senang dalam kegiatan wisata trekking. Disamping itu perlu adanya penambahan tenaga pengawas untuk Kawasan Hutan TWA Danau Buyan serta pembentukan kelembagaan khusus dalam pengelolaan Kawasan Hutan TWA Danau Buyan agar lebih terarah dengan memaksimalkan pemberdayaan masyarakat setempat. 


\section{Ucapan Terima Kasih}

Pada kesempatan ini perkenankanlah penulis mengucapkan terimakasih yang sebesar-besarnya kepada Prof. Dr. I Ketut Sudibia, SU dan Dr. Ir. Syamsul Alam Paturusi, MSP, selaku pembimbing I dan II tesis yang dengan penuh kesabaran telah memberikan bimbingan dan saran kepada penulis selama penyelesaian tesis dan penulisan artikel ini. Ucapan terimakasih yang sebesarbesarnya juga disampaikan kepada anggota penguji; Prof. Dr. I Nyoman Sirtha, SH, MS, Drs.I Nyoman Sunartha, M.Si, dan Dr. Ir. I Made Adhika, MSP atas bimbingan, saran sanggahan, koreksi, dan masukan, sehingga tesis ini dapat terselesaikan, para dosen dan staf administrasi Kajian Pariwisata atas segala bantuaannya dalam memperlancar proses perkuliahan

\section{Daftar Pustaka}

Butler, Richard. 1980. The Tourism Area Life Cycle: Applications and Modifications.

Great Britain: Crommwell Press.

Damanik, Janianton \& Weber, Helmut F.2006. Perencanaan Ekowisata dari Teori ke Aplikasi. Yogyakarta: Andi

Mikkelsen, 2003, Metode Penelitian Partisipatoris dan Upaya-upaya Pemberdayaan. Jakarta: Yayasan Obor Indonesia

Paturusi, Syamsul Alam. 2008. Perencanaan Kawasan Pariwisata. Denpasar. Udayanan University Press.

Rangkuti, Freddy. 2005. Analisis SWOT Teknik ,Membedah Kasus Bisnis. Jakarta: PT Gramedia Pustaka Utama.

Sukarsa. I Made.1999. Pengantar Pariwisata. Badan Kerjasama Perguruan Tinggi Negeri Indonesia Timur (BKS-PTN-INTIM)

Smith, Melanie K dan Robinson, Mike 2006. Culturer Tourism in a World, Politics, Participation and Representation, Great Britain, MPG Books

Yoeti, 1990: Pemasaran Pariwisata. Bandung: Angkasa.

\section{Profil Penulis}

I Ketut Budayasa menyelesaikan Program Studi S-2 Kajian Pariwisata Universitas Udayana tahun 2015. Tahun 2008 menyelesaikan kuliah S-1 di Fakultas Keguruan dan Ilmu Pendidikan (FKIP) Universitas Mahasaraswati Denpasar dengan gelar Sarjana Pendidikan (S.Pd). Tahun 2008 melanjutkan kuliah pada Program S-2 Pascasarjana Universitas Pendidikan Ganesha (Undiksha) Singaraja jurusan Administrasi Pendidikan dan tamat tahun 2011 dengan gelar Magister Pendidikan (M.Pd). Tahun 1983 - 1990 bekerja di Hotel Rama Garden Legian, dan tahun 19902009 bekerja di Ramada Bintang Bali Resort \& Spa. Dari tahun 2002 sampai sekarang sebagai guru di SMK Pariwisata Dalung, dan mulai tahun 2007 sebagai Instruktur di beberapa Lembaga Pelatihan Kerja (LPK) antara lain: PPKIP Jaya Wisata, LPK Monarch Gianyar, LPK Darma Mandala Renon, dan LPK Monarch Dalung. Tahun 2013 lulus sebagai Assesor Kantor Depan Perhotelan. 